\title{
A trama e a urdidura: o vocabulário têxtil e a história da língua portuguesa
}

\section{The warp and the weft: textile vocabulary and the history of the Portuguese language}

Gracinéa I. Oliveira ${ }^{1}$

RESUMO: O presente trabalho tem como objetivo analisar a formação do vocabulário têxtil na língua portuguesa, estabelecendo uma relação entre a formação desse vocabulário e as origens do português.

Palavras-chave: Vocabulário; Tecido; Língua portuguesa; História. Cultura.

\begin{abstract}
This paper aims to analyze vocabulary formation related to the textile world in the Portuguese Language by establishing a relationship between this vocabulary and the origins of the Portuguese Language.
\end{abstract}

Keywords: Vocabulary; Fabric; Portuguese Language; History; Culture.

\section{Apresentação}

Os tecidos permeiam o quotidiano das sociedades modernas. Presentes em quase todos os ambientes, eles acompanham o ser humano desde o nascimento até a morte. De aplicação diversa, mas usados principalmente na confecção de vestimentas, roupas de cama, mesa e banho, a invenção dos tecidos foi um ato "fundamental dos primeiros humanos" (Kvavadze et al, 2009: 1359), pois permitiu a confecção de roupas, cordas e cestos, itens esses que 
aumentavam consideravelmente as chances de sobrevivência e de mobilidade em condições adversas (Kvavadze et al, 2009:1359).

Mas o uso dos tecidos não ficou restrito apenas a fins práticos. Com o passar do tempo e com a diversificação das fibras, seu uso foi incorporando uma forte carga simbólica. Alguns tipos têxteis passaram a expressar poder, como o linho usado para embalsamar faraós, sumos sacerdotes e altas autoridades no Egito antigo (Chataignier, 2006: 32). Outros tecidos, como a seda, passaram a simbolizar status. Como exemplo, pode-se citar a Lei sobre os vestidos de seda, e feitio deles e das pessoas que os podem trazer, feita por Dom Sebastião, em 1.560 que restringia o uso da seda a algumas partes do vestuário e proibia rigorosamente as classes mais baixas de usá-la (Lei... apud Oliveira, 1998: 44). Com finalidade sensual, o linho já era usado na Antiguidade, visto que suas tramas frouxas e quase transparentes deixavam vislumbrar a nudez do corpo (CHATAIGNIER, 2006: 33).

Diante disso, percebe-se que os tecidos - itens corriqueiros - carregam nas suas tramas uma história que dialoga com a cultura do povo que os criou ou que os usa. Verdadeiros ícones de épocas e lugares, os tecidos costumam trazer nos próprios nomes a geografia do lugar onde foram fabricados ou difundidos e o percurso até determinada região.

Sendo assim, ou seja, devido à riqueza cultural materializada na trama dos tecidos, propõe-se, neste trabalho, verificar como se deu a formação do vocabulário têxtil na língua portuguesa. Mais especificamente, pretende-se tecer uma história entre língua e cultura tendo como fio condutor os nomes dos tecidos. Como é um vocabulário extremamente amplo, fez-se um recorte temporal e geográfico. Por isso, será analisada a formação do vocabulário dos tecidos das Minas Setecentistas.

Para a análise etimológica, foram pesquisadas as seguintes obras, nesta ordem de prioridade:

a) Dicionário Etimológico Nova Fronteira da Lingua Portuguesa de Antônio Geraldo da Cunha;

b) Dicionário Honaiss da Lingua Portuguesa de Antônio Houaiss e Mauro de Salles Villar.

E, para a montagem do corpus, foram consultados 26 inventários de pessoas brancas, sendo 13 de homens e 13 de mulheres que morreram nas 
Minas Gerais do século XVIII, mais precisamente na antiga Vila Real de Nossa Senhora da Conceição do Sabará, atual Comarca de Sabará, no Estado de Minas Gerais. Esses documentos estão sob a guarda do IBRAM na Casa de Borba Gato, situada na sede desse município. Desses inventários, 20 foram editados e publicados por Oliveira (2010, v.2: 209-834). Os outros 6 inventários foram editados para este trabalho, mas ainda não foram publicados. Para seleção das lexias, ou seja, para se saber se uma lexia pertencia ou não ao campo léxico dos tecidos, foram consultadas as seguintes obras, nesta ordem de prioridade:

a) Vocabulário portuguez e latino do padre Raphael Bluteau;

b) Diccionário da língua portugueza de Antônio de Morais Silva;

c) Dicionário Houaiss da Lingua Portuguesa de Antônio Houaiss e Mauro de Salles Villar;

À medida que foram encontradas, as lexias foram transcritas em uma tabela do programa Excel 2003, com a ortografia moderna. Em tabela à parte, no mesmo programa, foram sendo listados os lexemas correspondentes a cada lexia. Além das lexias, foram transcritos os demais elementos das frases em que elas ocorreram, além dos dados do inventário (incluindo número de fólios) ao qual cada lexia pertence. Posteriormente, para se saber o número de ocorrências de cada lexia, foi utilizada a ferramenta de busca do programa Excel 2003 que informou o número de vezes que a lexia ocorreu, ou seja, o número de células em que ela apareceu. Em relação às lexias compostas, para evitar enviesamento dos dados, como no caso de lexias compostas: baeta cochonilha, pano jardo, etc., em que o programa poderia conta as lexias pano e baeta mais de uma vez, a ferramenta de busca foi utilizada com a opção de coincidir conteúdo da célula inteira. As lexias não dicionarizadas, cujo contexto permitiu inferir que se tratava de tecido, foram incluídas no corpus. No caso de lexias polissêmicas, como riscado, que tanto podia signicar um tipo de tecido como o acabamento têxtil, foi utilizada a seguinte estratégia: quando designava o acabamento, teve a última consoante dobrada para que o excel não fizesse a contagem das lexias. 


\section{Origem dos tecidos e principais fibras}

Os tecidos foram desenvolvidos por povos que viviam em climas mais temperados, povos esses que inventaram o uso de fibras animais e vegetais para a confecção de roupas e utensílios domésticos.

Em relação à utilização das fibras de origem animal, é possível que a feltragem tenha sido o primeiro passo em direção à tecelagem. Nesse processo, desenvolvido na Ásia pelos ancestrais dos mongois, lã ou pelo de animais eram penteados, molhados e colocados em camadas sobre uma esteira. Posteriormente, enrolava-se a esteira e batia-se nela com uma vara. Os pelos e a lã eram dessa forma compactados e o feltro produzido era quente, maleável e durável, podendo ser costurado e moldado a fim de se fazerem roupas, tapetes e tendas (Laver, 2006).

Outra técnica primitiva que utilizava fibras vegetais era o aproveitamento de cascas de certas árvores, como a amoreira e a figueira. A casca era arrancada da árvore e mergulhada em água e três camadas dela eram colocadas sobre uma pedra chata de forma que a camada do meio formasse um ângulo com as outras duas. As camadas eram sovadas com um malho até que se juntassem e passava-se um óleo ou tinta para aumentar a durabilidade. Esse processo, muito parecido com o empregado pelos egípcios antigos na fabricação de papiro, pode ser considerado o intermediário entre a fabricação de esteiras e a tecelagem. Entretanto o tecido feito de casca era difícil de costurar e cortar, as roupas feitas com ele eram geralmente um retângulo com o qual se enrolava o corpo (Laver, 2006).

Fibras de casca de árvores foram utilizadas para tecer pelos índios americanos, mas não eram tão boas quanto as outras fibras vegetais como o linho, o cânhamo e o algodão. Essas últimas exigiam cultivo e foram pouco usadas na época pastoril (Laver, 2006).

Já a tecelagem em si exigia uma comunidade sedentária e cercada de bons pastos para ovelhas. O velo era tosquiado, o monte de fibras resultante era fiado e o fio era tecido em um tear. Uma vez estabelecida a manufatura de tecidos, mesmo em escala pequena, abriu-se o caminho para o desenvolvimento das roupas como são conhecidas atualmente (Laver, 2006).

Percebe-se, então, que o uso de tecidos remonta aos primórdios da humanidade: Idade da Pedra ou do Bronze disputam o título de época de surgimento 
dos primeiros tipos rudimentares de panos (Chataignier, 2006:20). Sendo o tecido a união de fios ou fibras até que se obtenha uma estrutura dimensional, a datação do aparecimento de um tecido está relacionada diretamente à descoberta das fibras têxteis de sua composição. As quatro fibras mais antigas são o linho - cerca de 10.000 a.C. - descoberto por habitantes primitivos de regiões lacustres, Mesopotâmia e Egito; a lã - cerca de 7.000 a.C - descoberta pelos povos da Mesopotâmia; o algodão - cerca de 3000 a.C - descoberto e cultivado no Paquistão e na Índia e a seda - cerca de 2.700 a.C. - descoberta na China (Chataignier, 2006:27-28).

\section{O Vocabulário Têxtil Das Minas Setecentistas: Na Trama Da História Da Língua Portuguesa}

Das regiões onde inicialmente foram manufaturados, os tecidos foram levados para diversas partes do mundo através do contato bélico e/ou comercial entre os povos. Um dos lugares para onde se levou diversos tipos de tecidos, a partir do século XVI, foi para o Brasil. Trazidos para cá pelos portugueses, logo se tornaram artigos de luxo cobiçados pela população local, principalmente pela população da região aurífera mineira.

Nas Minas Setecentistas, como no restante do Brasil Colônia, não havia fábricas têxteis. Por determinação da Metrópole só poderiam ser produzidos aqui "panos grossos que vestiam os escravos e aqueles destinados a fardos" (Lisanti, 1973). Esse fato teve como consequência a dependência do Brasil da importação de têxteis tanto da Metrópole quanto da Inglaterra e a proliferação de tecidos importados no território mineiro, visto que a descoberta de ouro disponibilizou capital para uma pequena elite local importar produtos europeus. Isso pode ser inferido pela variedade de lexemas e pela quantidade de lexias de tecidos e peles encontradas nos inventários pesquisados: 113 lexemas materializados em 1.560 lexias, conforme mostra a lista seguinte que traz a relação de lexemas seguidos da quantidade de lexias: ALGODÃo (40), ALiAgEm (14), ANiAgEm (8), ANTA (1), BAETA (98), BAETA COXONILHA (1), BAETÃo (6), BARregana (5), Belbute (2), Berberisco (6), BeZerro (6), Bigodinho (3), bocaXim (4), BOFETÁ (1), BRETANHA (76), BrilHANte (11), brim (7), CABAia (5), cadarço (15), calamanha (5), cambraia (14), cambraieta (6), CAmelão (40), camurÇa (4), CANequim (2), CANGa (5), carneiro (3), Cassa (29), Castor (12), 
Cetim (25), CHAMALOTE (10), CHita (45), CHitA-Fula (1), CORDOVÃo (1), CRÉ (3), CREPE (4), DAMASCO (4), Droguete (26), DROGUETE-REi (3), DUQUESA (1), DURANTE (29), DURANTE-REI (1), ENCERAdO (9), ENTREMEIO (2), ESCARDAdO (3), ESGUiÃo (7), ESPERMEgÃo (3), ESTAMENHA (3), ESTOFAdO (1), ESTOFO (5), ESTOPA (12), FiO (5), FITA (53), FLOCO (6), FUMO (7), FUSTÃO (7), GALA (7), GALÃO (10), GARÇA (2), GLACÊ (2), GRODETU (3), GUingão (1), holanda (26), HOLANDilha (5), LÃ (28), LAiA (10), Lemiste (12), LiNAGE (2), Linhagem (4), LiNho (103), LÓ (2), Lustro (4), maravalha (2), marroquim (4), melania (15), morim (1), NAStro (6), Negur (2), nobreza (6), PANico (7), PANO (205), PANO BERNE (1), PANO JARDO (1), PANO PEDRÊS (4), PANO SOL (1) PELE (10), PELÚCIA (5), PíCARO (2), PISÃo (4), PRIMOR (1), RENDA (28), REQUIFE (3), RETRÓS (39), RISCADILHO (2), RISCADO (22), RISSO (2), ROSAgRANA (2), RUÃo (18), SAETA (21), SARAÇA (2), SARAGOÇA (4), SARAGOÇão (1), SARJA (6), SEDA (130), SEDA DE CAVALO (2), SERAFina (10), SiLÉSia (3), TAFETÁ (28), TELA (4), TORÇAL (8), TRANCELIM (3), VELUdiLHo (3) e VELUdO (16).

Mas além da variedade lexical, outro indício de que os tecidos usados nas Minas provinham das mais diversas regiões é a presença de tecidos como bretanha, cambraia, damasco, holanda, ruão e saragoça. São tecidos cujos nomes são os mesmos dos locais (cidades ou países) onde outrora foram fabricados e/ou difundidos.

Além da presença desses tecidos cujos nomes são topônimos, os nomes dos têxteis, algumas vezes, vinham acompanhados por alguns qualificadores que indicavam o local de proveniência do tecido, como pode ser verificado pelos seguintes exemplos:

[Trezemeya] [v]arazde bertanhadeam / bur[go] vista eavaleadapellozditoz / avaliadores aquatro centoz esin / coenta reiz[en]porta em mil equi / nhentoz eset[ent]a esinco reiz; ${ }^{2}$

Hum retalho de Chita deBan / guela com Vinte eSeis covadoz / oqualSendo visto eaualiado por / eles ditos avaliadores por elles foi / avaliado CadaCovado atrezen / tos equarenta Reis que aotodo im

2 CARTÓRIO do Segundo Ofício de Notas, CSO I (47)349, f.4v - Inventário de Ana Maria da Rocha, 1777. IPHAN/IBRAM - Sabará - MG. 
/ porta aquantia deoito miloito / Centos equarenta Reis Com oque / SeSae fora amargem por algarismo; ${ }^{3}$

Sento eSincoenta equatroCouadoz / deRossa grana deCastella deVarias Cores / eemuarios Retalhos quefoj avalliado ca / daCouado a Mil equatro Sentos Reis que / emportaraõ todos em duzentos equinze / Mil eSeis Sentos Reis; ${ }^{4}$

Trinta e humCouadosdeSarja deFran / ça devarias Cores que foj avalliada Ca / daCouado a quinhentos eSesenta Reis / quetodos emportaraõ de(z)asete Mil e / trezentos eSeSenta Reis; ${ }^{5}$

Noue Couadoz deSeda Lavrada da / India avalliadaCada humCouado aoito / Sentos Reis quetodos emportaõ Sete / Mil eduzentos Reis; ${ }^{6}$

[apagado] peça depano Ingles com / [apagado] quatro couados etres que / [apagado] atres mil e dezesete reis / [e]mporta Setenta enoue mileduzentos;

Sento eSincoenta edous Couadoz / deSeda deItallia deVarias Cores eem / varios Retalhos quefoj avalliado cada / Couado a Mil eSeis Sentos Reis que / todos emportaraõ em duzentos equaren / ta etres Mil eduzentos Reis; ${ }^{8}$

3 CARTÓRIO do Primeiro Ofício de Notas, CPO I (07)78B, f.19r - Inventário de Custódio Pereira Rocha, 1778. IPHAN/IBRAM - Sabará - MG.

4 CARTÓRIO do Primeiro Ofício de Notas, CPO I(02)19, f.36v - Inventário de Matias Crasto Porto, 1742. IPHAN/IBRAM - Sabará - MG.

5 CARTÓRIO do Primeiro Ofício de Notas, CPO I(02)19, f.35v - Inventário de Matias Crasto Porto, 1742. IPHAN/IBRAM - Sabará - MG.

6 CARTÓRIO do Primeiro Ofício de Notas, CPO I(02)19, f.37r - Inventário de Matias Crasto Porto, 1742. IPHAN/IBRAM - Sabará - MG.

7 CARTÓRIO do Primeiro Ofício de Notas, CPO I (05)52, f.9r - Inventário de Fernando Pereira Guimarães, 1763. IPHAN/IBRAM - Sabará - MG.

8 CARTÓRIO do Primeiro Ofício de Notas, CPO I(02)19, f.35v - Inventário de Matias Crasto Porto, 1742. IPHAN/IBRAM - Sabará - MG. 
Setenta eSinco Couados deSeda / deRoma Pretta Lisa quefoj aualliado / cada Couado aMil eduzentos eSin / CoentaReis que todos emportaraõ em / Nouenta etres Mil Sete Sentos eSin / coenta Reis;

Concedo aLicença / que oSupplicante pede; porem / deue advertir Como / bom Pay defamilia / que aOrfã pode escuzar / aBertanba ditta deFrança, uzando / dehua deSilezia, oupano / de[†... fino. ${ }^{10}$

Junto à variedade lexical, aos topônimos e aos qualificadores toponímicos, a etimologia dos termos têxteis mostra que a urdidura dos tecidos tem como trama as culturas que contribuiram para a formação da língua portuguesa, como demonstra o GRAF.1:

\section{GRÁFICO 1 - etimologia dos lexemas}

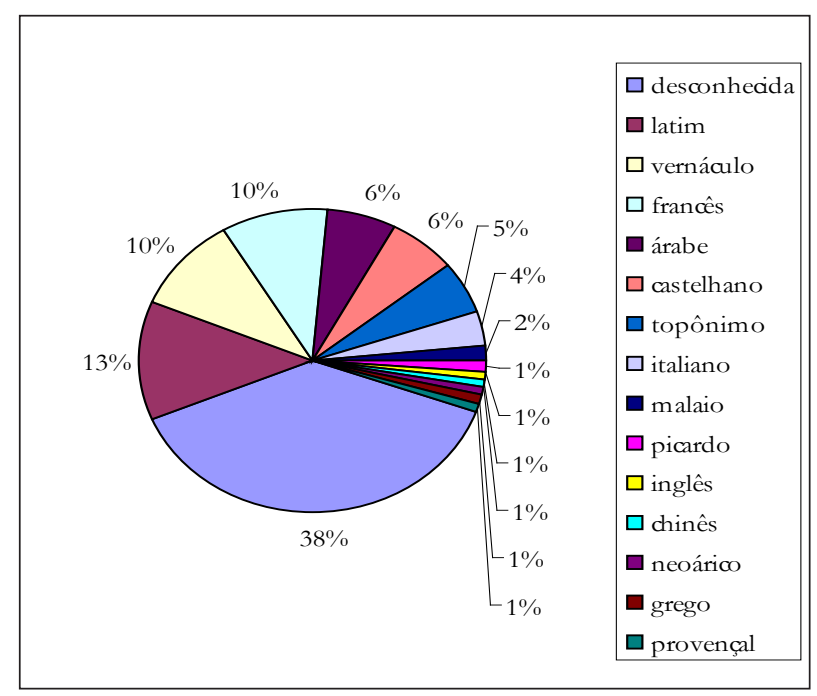

Pelo exposto no gráfico, verifica-se que diversas línguas contribuiram para a formação do vocabulário têxtil encontrado nas Minas do século XVIII.

9 CARTÓRIO do Primeiro Ofício de Notas, CPO I(02)19, f.36r - Inventário de Matias Crasto Porto, 1742. IPHAN/IBRAM - Sabará - MG.

10 CARTÓRIO do Segundo Ofício de Notas, CSO I (72)553, f.16ran - Inventário de Helena de Santa Teresa, 1795. IPHAN/IBRAM - Sabará - MG. 
Embora uma grande parte dos termos tenha étimo desconhecido (38\%), a maioria deles tem sua etimologia conhecida (62\%). É importante lembrar que foi considerada apenas a etimologia das palavras encontradas nos dois dicionários citados na primeira seção deste trabalho, salvo uma exceção que será comentada em nota.

Porém para se saber o padrão de constituição de um vocabulário qualquer, não basta apenas saber quais línguas contribuiram para sua formação. É necessário que se saiba como se deu a entrada dos vocábulos na língua: se por via hereditária, formação vernacular ou por empréstimo.

Entende-se como fonte hereditária do léxico português palavras oriundas das línguas faladas na Península Ibérica antes do domínio romano. É a chamada camada de substrato, camada essa composta por elementos ibéricos, célticos, gregos e fenícios (Cardoso; Cunha, 1978:132-134). Também faz parte do fundo hereditário do português as palavras do latim vulgar (fundo românico) e a língua falada pelos conquistadores da Península após o domínio de Roma. Essa última é a chamada camada de superstrato, composta por elementos germânicos (Vasconcelos, [19--]: 282) e pelo adstrato árabe (Basseto, 2001:163-168). No corpus, esse grupo é representado por 21 lexemas sendo 14 lexemas do latim

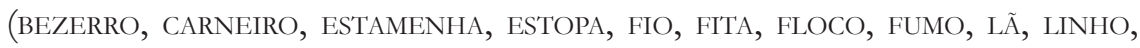
PANO, PELE, SEDA e TELA) e 7 do árabe (ALGODÃo, ANTA, BARREGANA, BOCAXIM, CABAIA, CETIM e MARROQUIM). A maioria desses lexemas teve as primeiras lexias registradas em português nos primórdios da língua, mais especificamente, nos séculos XIII (ALGODÃO, BEZERRO, CARNEIRO, FIO, FLOCO, FUMO, LÃ, LINHO, PANO, Pele, SEDA e tela) e XIV (estamenha, estopa, Fita). São herança do fundo românico e do domínio árabe na Península Ibérica. Estão nesse grupo os nomes dos quatro tecidos mais antigos do mundo: o algodão, a lã, o linho e a seda. De Roma os portugueses herdaram a fiação de peças de lã e de linho em cor natural e do Oriente islâmico importavam diversos tipos de tecidos (Marques, 1964:23-26). Esses dados mostram que os portugueses trouxeram para as Minas, além da língua, uma tradição milenar em matéria têxtil.

Entende-se por formação vernacular o processo pelo qual a língua forma novas palavras com seus próprios meios. Utilizando, por exemplo, recursos como afixos ou combinando elementos autônomos, são formadas novas palavras para expressar ideias novas ou nomear novos objetos (Melo, 1975:218-227). Diversos são os processos de formação vocabular, mas é pos- 
sível, sucintamente, reduzi-los a dois: derivação e composição, frisando que existem outros (Cunha; Cintra, 2001:83). No corpus, esse grupo é representado por 11 lexemas (BAETÃo, CAMBraieta, CAMELÃo, DUQuesa, ENTREMEIO, ESTOFAdo, NOBREZA, PISÃO, RISCADO, SARAGOÇÃO e VELUDILHO) sendo que a maioria foi formada por derivação, exceto ENTREMEIO que foi formado por composição.

Já palavras de empréstimo são aquelas que não participam do núcleo hereditário do léxico e integram, sob a forma de contribuição de outros idiomas, o seu pecúlio verbal. São os seguintes elementos que contribuíram com empréstimos ao léxico do português: o elemento provençal; o elemento latino (palavras que, no Renascimento, vieram por via erudita ou foram reconduzidas aos modelos latinos); o elemento oriental (africanos e asiáticos) e o elemento originário de línguas modernas (Cunha; Cardoso, 1978:137-146), como, por exemplo, o espanhol (Vasconcelos, [19--]:323), o francês, o inglês, o italiano, o alemão, etc. (Cunha; Cardoso, 1978:137-146). No corpus esse grupo é representado por 38 lexemas distribuídos conforme QUADRO 1:

\section{QUADRO 1}

Distribuição dos lexemas de empréstimo

\begin{tabular}{|l|l|}
\hline Lingua & Lexema \\
\hline provençal & VELUDO \\
\hline castelhano & $\begin{array}{l}\text { CADARÇO, CORDOVÃO, HOLANDILHA, } \\
\text { LEMISTE, RENDA, TORÇAL, TRANCELIM }\end{array}$ \\
\hline Latim & CAMURÇA e CASTOR \\
\hline malaio & CASSO, GUINGÃO e SARAÇA \\
\hline chinês & GANGA \\
\hline neoárico & CHITA \\
\hline francês & $\begin{array}{l}\text { BRIM, CHAMALOTE, CREPE, DROGUETE, } \\
\text { ESTOFO, GALÃO, GRODETU, LINHAGEM, } \\
\text { RETRÓs, SARJA e TAFETÁ }\end{array}$ \\
\hline italiano & DURANTE, GALA, NASTRO e PELÚCIA \\
\hline flamengo & FUSTÃO \\
\hline
\end{tabular}




\begin{tabular}{|l|l|}
\hline picardo & BAETA \\
\hline inglês & BELBUTE \\
\hline grego & MELANIA \\
\hline topônimos & $\begin{array}{l}\text { BRETANHA, CAMBRAIA, DAMASCO, HO- } \\
\text { LANDA, RUÃO e SARAGOÇA }\end{array}$ \\
\hline
\end{tabular}

Em relação aos lexemas de origem provençal, latina e asiática verificou-se que os primeiros registros na língua portuguesa remontam ao século XV (VELUDO), passando pelos séculos XVI (GANGA, GUINGÃO e SARAÇA), XVII (CASSA) e XVIII (CHITA, CAMURÇA E CASTOR $^{11}$ ). Desse conjunto, o provençal apresentou o registro mais antigo: século XV. Embora a influência do provençal na constituição do léxico português tenha sido sentida principalmente nos primórdios da língua - século XIII - através dos trovadores provençais (Cardoso; Cunha. 1978:159), no vocabulário têxtil a contribuição dessa língua ocorreu um pouco mais tarde. Talvez isso se explique pelo fato de o lexema de origem provençal - VELUDO - designar um tipo de tecido que se desenvolveu justamente entre os séculos XV e XVI (Copolla, 2006:117).

Em relação às línguas asiáticas (malaio, chinês e neoárico), a entrada de termos têxteis se deu principalmente nos século XVI (GANGA, GUINGão e SARAÇA). Os outros dois séculos - XVII e XVIII - tiveram um registro cada (CASSA e CHITA). A contribuição dessas línguas pode ser associada à expansão ultramarina portuguesa iniciada no final do século XV e concretizada nos séculos posteriores. A data de entrada dos lexemas na língua confere com a cronologia das conquistas portuguesas.

Pertencem às línguas europeias modernas grande parte dos lexemas desse grupo: 67\%. Isso é indício de que a maioria dos tecidos que chegava às Minas não era manufaturada em Portugal, visto que Portugal, “à época, tinha uma produção manufatureira diminuta e funcionava como um entreposto entre as

11 Datação: 1813 (CUNHA, 1990:163) Entretanto foi necessário retrodatar, visto que esse termo foi encontrado em um inventário de 1742: "Sincopares deLuuas deCastor de / home a Seis Sentos Reis quetodas em / portaõ em tres Mil Reis" (CARTÓRIO do Primeiro Ofício de Notas, CPO I(02)19, f.44r - Inventário de Matias Crasto Porto, 1742. IPHAN/IBRAM - Sabará - MG) 
diversas praças europeias" (Zemella apudDrumond, 2009:198). Como o grupo é muito grande, será analisada a contribuição de cada língua separadamente.

Nesse grupo, o francês foi a língua que mais contribuiu para a formação do vocabulário têxtil. Remonta aos primórdios da língua portuguesa a presença de termos têxteis de origem francesa: século XIII (LINHAGEM e SARJA), passando pelos séculos XIV (CHAMALOTE), XV (RETRÓs), XVI (TAFETÁ), XVII (ESTOFO) e XVIII (BRIM, CREPE, DROGUETE, GALÃO e GRODETU ${ }^{12}$ ). A influência do francês nos primórdios da formação da língua portuguesa pode ser relacionada ao fato de a constituição de Portugal como Estado monárquico ser consequência do casamento de um nobre francês - D. Henrique, conde de Borgonha - com Tareja, filha bastarda de D. Afonso VI, rei de Leão e Castela. O casamento de Dom Henrique com Tareja e a doação do feudo, o Condado Portucalense desmembrado do território da Galiza, foi um prêmio recebido por Dom Henrique pelo sucesso na luta pela expulsão dos mouros (Hauy, 1989). Após a morte de Dom Henrique, coube a seu filho Dom Afonso Henriques expulsar definitivamente os árabes e sagrar-se rei de Portugal (Cardoso; Cunha, 1978, p.51-52). A continuação dos empréstimos pode ser relacionada a alianças políticas, como o auxílio dos soldados franceses a D. João IV na guerra contra a

12 Embora não haja registro desse lexema nos dicionários de língua portuguesa consultados, foi possível inferir que se trata de um tecido pelos contextos das ocorrências, como mostram as abonações: "Por sette covados deseda preta la / vrada grodetú que foy avaliada ca / da Covado amil eseis Sentos Reis aotodo / honzemil edusentos Reis" (CARTÓRIO do Primeiro Ofício de Notas, CPO I(02) 23A, f.7v - Inventário de Manoel da Costa Rios, 1744. IPHAN/IBRAM - Sabará - MG); "Por trese Covados de grodetude / Cor quefoyavaliado cada hum / amil eseis sentos reis ao todo / emporta em vinte mil e(digo)mil / eoutocentos Reis" (CARTÓRIO do Primeiro Ofício de Notas, CPO I(02) 23A, f.8r - Inventário de Manoel da Costa Rios, 1744. IPHAN/IBRAM). Foi possível inferir que se trata de um galicismo pelos seguintes motivos: a) por haver referência a esse tipo de tecido em obras especializadas, embora tragam a grafia francesa: “(...) Gros de Tour: ponto derivado do tafetá, em que os fios da trama são remetidos, cada um de uma vez, por duas vezes, para se obter uma perfeita separação e paralelismo nos cruzamentos da trama com a urdidura." (COPPOLA, 2006:89); em um glossário de têxteis: "Gros de Tours - (fr.) Tecido de seda de trama grossa, tecnicamente derivado da armadura da tela, obtido pela duplicação do fio da trama.” (COSTA, 2004:148) e em um dicionário de francês: “(...) Gros de Tours: étoffe de soie à gras grains fabriquée autrefois dans ces villes.” (MORTIER, 1948, v.2:872); b) o fato de ser comum a importação de tecidos da cidade de Tours desde o século XIII, conforme afirmação de um especialista: "Do seculo XIII, não faltam documentos que nos dizem claramente recebermos pannos de Gand, Ypres, Chardes, Abbeville, Arras, Tours, Lille (...)" (PESSANHA, 1923, v.3:41) Pelo exposto, verifica-se que a grafia portuguesa corresponde à pronúncia francesa. 
Espanha (Vasconcelos, [19--]:15) e, principalmente, à influência que a França exerceu no campo da moda. Influência essa que se iniciou no século XVII e se consolidou no século XVIII (Köhler, 2001). Confirma tal influência o fato de a maioria dos lexemas têxteis de origem francesa terem entrado na língua no século século XVIII. Além disso, nesse século, o espanhol deixou de desempenhar o papel de segunda língua de cultura em Portugal e o francês passou a exercer tal função (Teyssier, 1990).

A segunda língua moderna que mais contribuiu para a formação do vocabulário têxtil foi o castelhano. Remonta, também, aos primórdios da língua a presença de termos têxteis de origem espanhola: século XIII (CADARÇO, CORDOVÃO e RENDA), passando pelos seculos XVI (TORÇAL), XVII (TRANCELIM) e XVIII (LEMISTE, HOLANDILHA). Essa antiguidade pode ser explicada pela relação muito estreita que houve entre os Reinos de Portugal e Castela. Essa relação se dava através de casamentos entre soberanos portugueses com princesas espanholas, tradição essa que permaneceu até o século XVII resultando em certa castelhanização da corte. $\mathrm{O}$ espanhol serviu como segunda língua para todos os portugueses cultos nesse período. Apenas após a Restauração e a subida ao trono de Dom João IV, houve uma reação anti-espanhola. Todavia, o bilingüismo permaneceu até o desaparecimento dos últimos representantes da geração formada antes de 1640 (Teyssier, 1990). Junto a isso pode-se acrescentar o fato de a Espanha ter exercido uma influência grande no vestuário europeu de meados do século XVI até parte do século XVII (Laver, 2006, p.88-103). Pistas desse estreitamento político, linguístico e cultural podem ser colhidas no vocabulário dos tecidos, visto que há entrada, também, de termos têxteis de origem castelhana nos séculos XVI, XVII e XVIII.

A terceira língua moderna europeia que mais contribuiu para a formação do vocabulário têxtil foi o italiano. São termos que entraram na língua entre os séculos XVII (GALA) e XVIII (DURANTE, NASTRO ${ }^{13} \mathrm{e}$ PELÚCIA). Tal contribuição pode ser relacionada ao comércio, visto que de importantes mercados italiano como Gênova, Veneza, Roma e Milão

13 Datação: 1813. (Cunha, 1990:545) Entretanto foi necessário retrodatar, visto que esse termo foi encontrado em um inventário de 1742: "Des pessas deNastro Branco quefoj a/ valliadaCada pessa aSemReis quetodas / emportaraõ Mil Reis" (CARTÓRIO do Primeiro Ofício de Notas, CPO I(02)19, f.44v - Inventário de Matias Crasto Porto, 1742. IPHAN/ IBRAM - Sabará - MG) 
sairam diversos tecidos (Drumond, 2008:35-36) que foram aportar às Minas Setecentistas.

As demais línguas, flamengo, picardo, inglês e grego contribuiram com um lexema cada, respectivamente, FUSTÃo, BAETA, BELBUTE e MELANIA. Excetuando BAETA que entrou na língua no século XVI, os demais entraram no português no século XVIII. A entrada desses termos sobretudo na época Setecentista é fruto das relações comerciais portuguesas. Conforme já dito, tecidos, peças e acessórios de várias partes do mundo como Holanda, Espanha, Goa, Diu, Itália, França, Inglaterra, dentre outras, chegaram até as lojas da então Capitania de Minas. Lojas essas que além de vender panos e roupas contribuíram para reproduzir, através dos modelos dos tecidos, parte do universo cultural do colonizador e daqueles com os quais ele entrou em contato através do comércio (Drumond, 2008:36). Podem ser atribuídos também a relações comerciais os 6 lexemas de origem toponímica: BRETANHA, CAMBRAIA, DAMASCO, HOLANDA, RUÃO e SARAGOÇA.

Veja-se, então, a distribuição das fontes de constituição do vocabulário têxtil no GRÁF. 2:

\section{GRÁFICO. 2 - Fontes do vocabulário têxtil}

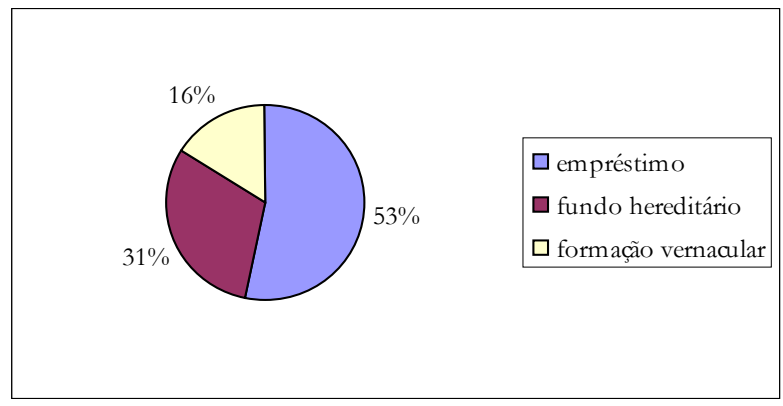

Conforme mostra o gráfico, a maior parte dos lexemas dos tecidos é oriunda de empréstimos linguísticos. Isso mostra que o intenso câmbio de mercadorias, tecnologias e modas entre portugueses e outros povos acabou contribuindo para aumentar consideravelmente esse vocabulário especializado. 


\section{Considerações finais}

Como dito no início deste trabalho, os tecidos carregam em suas fibras uma história milenar que se envereda pelos primórdios da humanidade. Utilizados inicialmente com fins práticos, tiveram o uso diversificado até a aplicação na área de embelezamento. Muitas fibras foram conhecidas e confeccionadas por civilizações milenares que legaram à modernidade toda uma tradição em matéria têxtil.

Como mostra dessa herança milenar pode-se citar os lexemas têxteis que entraram na língua portuguesa por forma hereditária. Designam fibras milenares cuja técnica e/ou uso foram passadas por civilizações antiquíssimas, como a grega, a árabe e a latina.

Mas o intercâmbio cultural de têxteis não se restringe a essas civilizações antigas. Na época moderna, as técnicas de tecidos continuaram desenvolvendo-se e expandiram para diversos locais. Pistas desses cruzamentos culturais advindos de câmbios políticos, comerciais e/ou bélicos podem ser colhidas no próprio vocabulário têxtil do português, visto que a maioria desses termos entraram na língua através de empréstimos linguísticos.

Mas não apenas de herança ou empréstimo é formado esse vocabulário. Usando recursos da própria língua, novos termos foram criados para designar tipos diversos de tecidos.

Pelo exposto, verifica-se que pela urdidura da língua, a trama dos tecidos tece uma história que se funde à própria história da formação da língua portuguesa.

\section{Referências bibliográficas}

BLUTEAU, Raphael. Vocabulário portuguez, latino, aulico, anatomico, architectonico...Coimbra: Collegio das Artes da Companhia de Jesu, 1712-1728. 8 v. (CD-ROM).

BASSETO, Bruno Fregni. (2001 ). Elementos de filologia românica. São Paulo: Edusp. CUNHA, Antonio Geraldo da. (1997). Dicionário etimológico Nova Fronteira. 2. ed. Rio de Janeiro Nova Fronteira.

CUNHA, Celso; CINTRA, Lindley. (2001). Nova gramática do português contemporâneo. 3. ed. Rio de Janeiro: Nova Fronteira. 
CARDOSO, Wilton; CUNHA, Celso. (1978). Estilistica e gramática histórica: português através de textos. Rio de Janeiro: Tempo Brasileiro.

CHATAIGNIER, Gilda. (2006). Fio a fio: tecidos, moda e linguagem. São Paulo: Estação das Letras.

COPPOLA, Soraya Aparecida Álvares. (2006). Costurand a memória: o acervo têxtil do museu arquidiocesano de arte sacra de Mariana. Dissertação (Mestrado em Artes Visuais) - Escola de Belas Artes da Universidade Federal de Minas Gerais, Belo Horizonte. COSTA, Manuela Pinto da. (2004). Glossário de termos têxteis e afins. Revista da faculdade de Letras: ciências e técnicas do patrimônio, Porto, v.3, p.137-161. Disponível em: <http://ler.letras.up.pt/uploads/ficheiros/4088.pdf>. Acesso em 29 out. 2009.

DRUMOND, Marco Aurélio. (2008). Indumentária e Cultura Material: Produção, comércio e usos na Comarca do Rio das Velhas (1711-1750). Dissertação (Mestrado em História) - Faculdade de Filosofia e Ciências Humanas da Universidade Federal de Minas Gerais: Belo Horizonte, .

HAUY, Amini Boainain. (1989). História da língua portuguesa: séculos XII, XIII e XIV. São Paulo: Ática.

HOUAISS, Antônio; VILLAR, Mauro de Salles. (2009). Dicionário Houaiss da Lingua Portuguesa. Rio de Janeiro: Objetiva.

KVAVADZE, Eliso et al. (2009). 30,000 - year - Old Wild Flax Fibers. Science, v.325, n.5946, p.1359. Disponível em: <www.sciencemag.org.>. Acesso em 16 dez. 2009.

KÖHLER, Karl. (2005). História do vestuário. São Paulo: Martins Fontes.

LAVER, James. (1989). A roupa e a moda: uma história concisa. São Paulo: Companhia das Letras.

LISANTI, Luis. (1973). Negócios coloniais: uma correspondência comercial do século XVIII. Brasília: Ministério da Fazenda; São Paulo: Visão editorial, 5v.

MARQUES, A. H. de Oliveira. (1964). A sociedade medieval portuguesa. Lisboa: Livraria Sá da Costa editora.

MELO, Gladstone Chaves. (1975). Iniciação à Filologia e à Linguistica Portuguesa. 5.ed. Rio de Janeiro: Livraria Acadêmica.

MORTIER, Raoul (dir). (1948). Dictionnaire quillet de la langue française: dictionnaire méthodique et pratique rédigé sous la direction de Raoul Mortier "L'art d'écrire et de bien rédiger." Paris: Librairie Aristide Quillet, 3 vol.

OLIVEIRA, Fernando José Cunha de. (1998). O vestuário português ao tempo da expansão: séculos XV e XVI. [S.1]: Grupo de trabalho do Ministério da Educação para os Descobrimentos Portugueses. 
OLIVEIRA, Gracinéa I. (2010). Estudo do vocabulário do vestuário em documentos setecentistas de Minas Gerais. Dissertação (Mestrado em Letras) - Faculdade de Letras da Universidade Federal de Minas Gerais, Belo Horizonte, 2vol.

PESSANHA, Sebastião. (1923). Os primeiros tecidos portugueses. Contemporânea: grande revista mensal, Lisboa, v.3, n. 8, p.40-42. Disponível em: <http://hemerotecadigital.cm-lisboa.pt/OBRAS/CONTEMPORANEA/1923/N7/N7_item1/ P48.html>. Acesso em 22 dez. 2010.

SILVA, Antônio de Morais. (1922). Dicionário da língua portuguesa. Rio de Janeiro: Revista de Língua Portuguesa. 2t. [Edição fac-similar da segunda edição, de 1813.]

TEYSSIER, Paul. (1990). História da língua portuguesa. 4. ed. Lisboa: Livraria Sá da Costa Editora.

VASCONCELOS, Carolina Michaëlis de. (19[--]Lições de filologia portuguesa: segundo as preleções feitas aos cursos de 1911/12 e de 1912/13. Lisboa: Livraria Martins Fontes.

ZEMELLA, Mafalda P. (1951). O abastecimento da capitania das Minas Gerais no século XVIII. São Paulo: [s.n.].

Recebido em: 30/12/2010

Aprovado em: 02/05/2011 